\title{
Pengaruh Karakteristik Individu Terhadap Perilaku Kerja Aman pada Pekerja di PT. Karya Muda Belia
}

\author{
Elisa Hafrida ${ }^{1}$, Widy Seprianto ${ }^{2}$ \\ 1,2) Program Studi Teknik Industri, Sekolah Tinggi Teknologi Dumai \\ Jl. Utama Karya Bukit Batrem II \\ Email : hafridae@gmail.com
}

\begin{abstract}
ABSTRAK
Penelitian ini bertujuan untuk mengetahui pengaruh pengetahuan, persepsi dan alat pelindung diri terhadap perilaku kerja aman pada pekerja di PT. Karya Muda Belia. Populasi sebanyak 40 orang pekerja pipa. Penelitian ini menggunakan teknik sampling jenuh dimana penentuan sampel terdiri dari semua anggota populasi. Pengumpulan data menggunakan kuesioner. Teknik analisis data yang digunakan yaitu analisis regresi linier berganda untuk mengetahui pengaruh variabel-variabel bebas (pengetahuan, persepsi dan alat pelindung diri) terhadap variabel terikat (perilaku kerja aman) dengan pengujian hipotesis uji $\mathrm{F}$ dan uji T. Hasil penelitian ini menunjukkan variabel-variabel bebas secara bersama-sama berpengaruh terhadap variabel terikat dengan ditunjukkan nilai Fhitung $(3,238)$ lebih besar dari Ftabel $(2,87)$ dan nilai $\mathrm{R}^{2}$ sebesar 0,149 atau $14,9 \%$, artinya variabel-variabel bebas (pengetahuan, persepsi, dan alat pelindung diri) berpengaruh terhadap variabel terikat (perilaku kerja aman) dan sisanya $85,1 \%$ dipengaruhi oleh variabel lainnya, dan untuk variabel yang paling berpengaruh yaitu persepsi dan alat pelindung diri.
\end{abstract}

Kata kunci: Karakteristik Individu, Perilaku Kerja Aman, Pekerja.

\begin{abstract}
The purpose of this research is to determine the effect of knowledge, response, and personal safety equipment against the behavior of safe work on pipe workers at Karya Muda Belia company. The population of this research is 40 pipe workers. This research used a saturation sampling technique where the determination of the samples and all members of the population Data collected using a questionnaire. Data analysis techniques used multiple linear regression techniques to determine the effect of independent variables (knowledge, perception and personal safety equipment) towards the dependent variables (behavior of safe work) with the hypothesis used the F test and $T$-test. The results of this research indicate that the independent variables (knowledge, perception and personal protective equipment) cooperate to measure the dependent variables (behavior of safe work) with showed the value of Fcount $(3,238)$ is more significant than Ftable (2.87) and $R^{2}$ values are 0,149 or 14,9\% means independent variables (knowledge, perception and personal safety equipment), and the remaining are $85,1 \%$ which is influenced by other variables, and for the most influential variables are perception and Personal protective equipment.
\end{abstract}

Keywords: Characteristic individuals, Behavior-Based Safety, Worker. 


\section{Pendahuluan}

Perilaku kerja aman adalah aspek penting dalam kajian behavior based safety. Perilaku aman adalah tindakan atau perbuatan dari seseorang atau beberapa orang karyawan yang memperkecil kemungkinan terjadinya kecelakaan terhadap karyawan (Halimah, S. 2010). Adapun jenis-jenis perilaku kerja aman adalah : melakukan pekerjaan sesuai wewenang yang diberikan, berhasil memberikan peringatan terhadap adanya bahaya, menggunakan peralatan yang seharusnya, menggunakan APD dengan benar, dan lain-lain.(E. Bid dan Germain, 1990). Menurut data dari BPJS Ketenagakerjaan Indonesia terjadi penurunan kasus kecelakaan kerja sebanyak 4,6\% yaitu tahun 2015 terjadi 110.285 kasus dan tahun 2016 terjadi 105.182 kasus. Kemudian sampai bulan Agustus tahun 2017 sebanyak 80.392 kasus.

PT. Karya muda belia adalah salah satu perusahaan yang bergerak di bidang pipa, perusahaan ini merupakan perusahaan mitra bisnis (kontraktor) dari PT. X. Berdasarkan peninjauan di lapangan, bahwa para pekerja sudah melakukan pekerja aman. Dimana pekerja sudah menggunakan APD yang baik dan benar serta melakukan pekerjaan sesuai SOP yang sudah ada. Hal ini dilihat tercapainya zero accident pada tahun 2017 dan 2018, sehingga peneliti ingin mengetahui faktor apa saja yang berpengaruh terhadap tercapainya zero accident. Berdasarkan latar belakang di atas penulis tertarik melakukan penelitian dengan judul "Pengaruh karakteristik individu terhadap perilaku kerja aman pada pekerja pipa di PT. Karya Muda Belia”.

\section{Metode Penelitian}

Penelitian ini dilakukan di PT Karya Muda, Jalan Raya Kilang Putri Tujuh. Penelitian dilaksanakan pada tanggal 22 Januari s/d 22 Mei 2019. Populasi yang digunakan pada penelitian ini adalah 40 pekerja pipa., dengan menggunakan teknik non probability sampling, yaitu teknik sampling jenuh dimana penentuan sampel berasal dari semua anggota populasi. Jenis data yang digunakan yaitu data kuantitatif dan data kualitatif, dimana data kualitatif seperti gambaran umum perusahaan, dan data-data yang menunjang penelitian, sedangkan data kuantitatif berupa angka yang dapat dihitung seperti hasil rekap kuesioner. Sumber data yang digunakan adalah data primer dan data sekunder. Data primer yaitu data yang diperoleh peneliti melalui observasi atau pengamatan langsung, baik itu melalui observasi, wawancara dan kuesioner secara langsung dengan responden, sedangkan data sekunder adalah data yang mendukung data primer diperoleh dari dokumen perusahaan, literatur atau referensi yang berupa buku-buku, jurnal, dan skripsiskripsi yang berisikan petunjuk tentang semua informasi terkait.

Metode yang digunakan dalam pengambilan data adalah menggunakan kuesioner, yaitu teknik yang dilakukan dengan mengajukan pertanyaan secara tertulis kepada responden. Teknik analisis data pada penelitian ini yaitu dengan dilakukan uji asumsi klasik seperti : uji normalitas, uji multikolinearitas, uji heteroskedastisitas, dan uji hipotesis seperti : uji F (uji simultan) yaitu pengujian 
regresi secara simultan atau serentak antara variable independen terhadap variable dependen, dan uji $\mathrm{T}$ (Uji Parsial) yaitu pengujian regresi secara terpisah atau parsial antar masing-masing variabel independen terhadap variabel dependen.

\section{Hasil dan Pembahasan}

\section{A. Hasil Penelitian}

\section{Uji Asumsi Klasik}

Pengujian asumsi klasik dilakukan dengan menggunakan uji normalitas, uji multikolinieritas, dan uji heteroskedastisitas.

\section{a) Uji Normalitas}

Uji normalitas digunakan untuk mengetahui apakah data berdistribusi normal atau tidak. Uji ini biasanya digunakan untuk mengukur data berskala ordinal, interval ataupun rasio.

Tabel 1. Hasil output uji normalitas

One-Sample Kolmogorov-Smirnov Test

\begin{tabular}{|ll|r|}
\hline & & $\begin{array}{c}\text { Unstandardized } \\
\text { Residual }\end{array}$ \\
\hline$N$ & Mean & 40 \\
Normal Parameters & \\
& Std. Deviation & .0000000 \\
Most Extreme Differences & Absolute & 1,47990412 \\
& Positive & .100 \\
& Negative & .074 \\
Kolmogorov-Smirnov $Z$ & & -.100 \\
Asymp. Sig. (2-tailed) & & .100 \\
\hline Test distribution is Normal. & & .200 \\
\hline
\end{tabular}

Berdasarkan Tabel 1 hasil output uji normalitas di atas menggunakan uji onesample Kolmogorov-Smirnov, diketahui bahwa nilai signifikan 0,200 atau lebih besar dari 0,05 maka dapat disimpulkan bahwa populasi data berdistribusi normal.

\section{b) Uji Multikolinearitas}

Multikolinearitas adalah keadaan dimana terjadi hubungan linier yang sempurna atau mendekati sempurna antar variabel independen, digunakan untuk mengetahui ada atau tidaknya hubungan linier antar variabel independen dalam model regresi. Suatu model regresi menunjukkan adanya multikolinearitas jika : tingkat korelasi $>$ $95 \%$, nilai toleransi $<0,10$, dan nilai VIF $>10$. 
Tabel 2. Hasil output uji multikolinearitas

\begin{tabular}{|c|c|c|c|c|c|c|c|}
\hline \multicolumn{8}{|c|}{ Coefficients } \\
\hline \multirow{2}{*}{ Mode1 } & \multicolumn{2}{|c|}{ Unstandardized Coefficent } & \multirow{2}{*}{$\begin{array}{c}\begin{array}{c}\text { standardized } \\
\text { Coeffic ent }\end{array} \\
\text { Beta } \\
\end{array}$} & \multirow{2}{*}{$\mathrm{t}$} & \multirow{2}{*}{ sig } & \multicolumn{2}{|c|}{ Collinearity Statis tic } \\
\hline & B & Std.eror & & & & Tollerance & VIF \\
\hline (Constanta) & 4,206 & 3,432 & & 1,226 & .228 & & \\
\hline pengetahuan & $-0,058$ & .151 & $-0,061$ & $-0,383$ & .704 & 930 & 1.074 \\
\hline persepsi & .543 & .234 & .725 & $-2,319$ & .026 & .241 & 4.148 \\
\hline alat pelindung diri & $-0,489$ & .194 & $-0,083$ & $-2,523$ & .016 & .223 & 4.297 \\
\hline 2. (Constanta) & 3,797 & 3,223 & & 1,178 & 246 & & \\
\hline Persepsi & .529 & .228 & .706 & 2.314 & .026 & 247 & 4,046 \\
\hline Alat Pelindung diri & $-0,471$ & .186 & $-0,773$ & $-2,534$ & .016 & 247 & 4,046 \\
\hline
\end{tabular}

Berdasarkan Tabel 2 hasil output Coefficientsa dapat dilihat kolom VIF diketahui bahwa nilai VIF untuk variabel bebas berada di bawah 10. Karena nilai VIF kurang dari 10, maka dapat disimpulkan bahwa pada model regresi tidak ditemukan adanya masalah multikolinearitas.

\section{c) Uji Heteroskedastisitas}

Heteroskedasititas adalah keadaan dimana terjadi ketidaksamaan varian dan residual untuk semua pengamatan pada model regresi. Untuk melihat uji heteroskedastisitas dengan menggunakan uji grafik regresi dan correlation. Uji grafik regresi yaitu dengan melihat grafik plot antara nilai prediksi variabel dependen dengan residualnya dan melihat ada tidaknya pola tertentu pada grafik scatterplot. Jika ada pola tertentu, seperti titik-titik yang ada membentuk suatu pola yang teratur (bergelombang, melebar, kemudian menyempit), maka mengindikasikan telah terjadi heteroskedastisitas. Jika tidak ada pola yang jelas, serta titik-titik menyebar di atas dan di bawah angka 0 pada sumbu $Y$, tidak terjadi heteroskedastisitas.

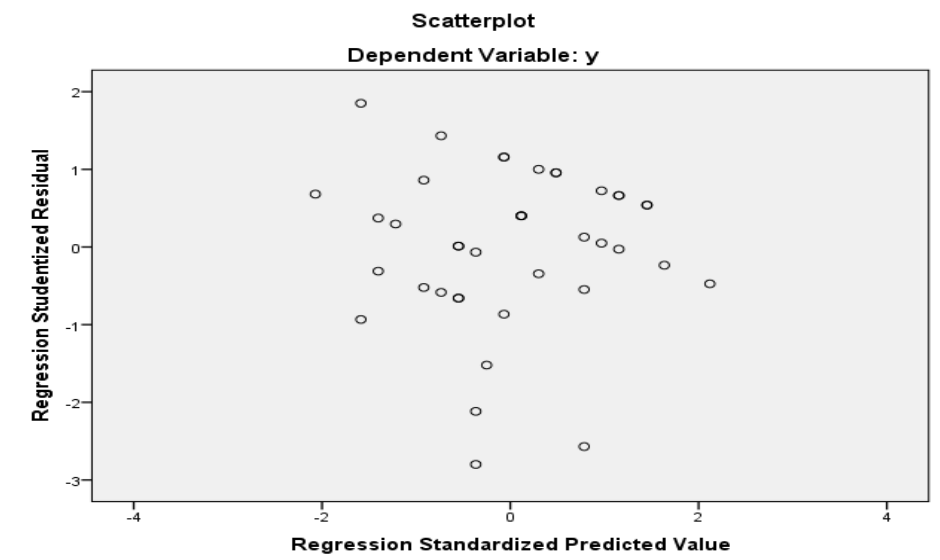

Gambar 1. Hasil output uji heteroskedastisitas menggunakan grafik regresi

Gambar 1 terlihat bahwa sebaran titik tidak membentuk suatu pola/alur tertentu, sehingga dapat disimpulkan tidak terjadi heteroskedastisitas atau dengan kata lain terjadi homoskedastisitas. Asumsi klasik tentang heteroskedastisitas dalam model ini terpenuhi, yaitu terbebas dari heteroskedastisitas. 
Tabel 3. Hasil output uji multikolinearitas

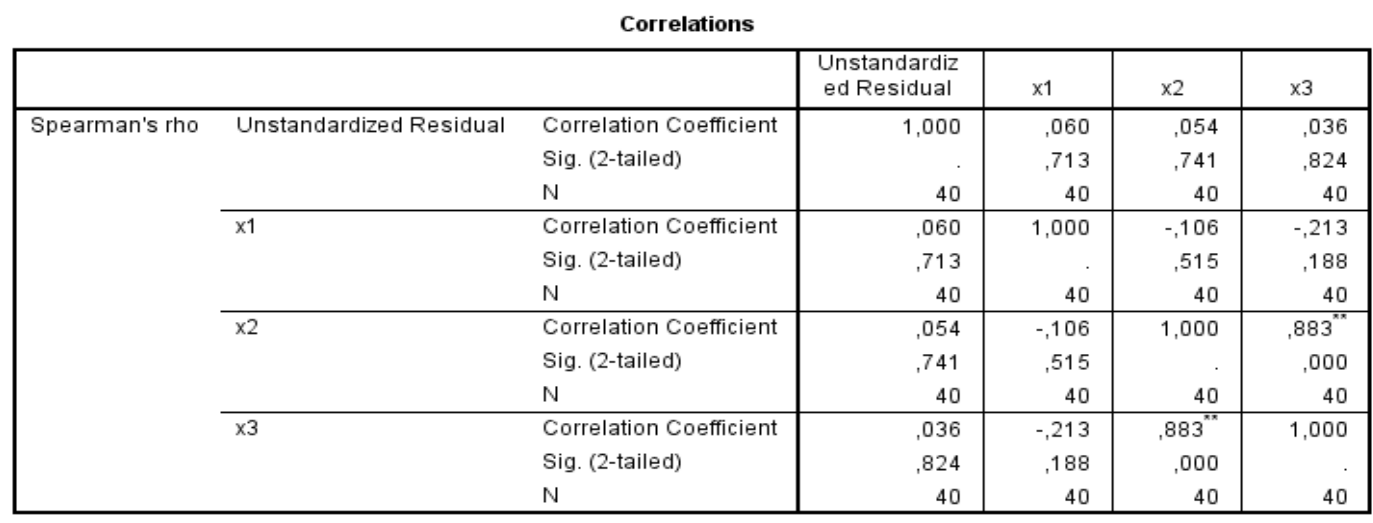

**. Correlation is significant at the 0.01 level (2-tailed).

Berdasarkan Tabel 3 diketahui nilai signifikasi lebih dari 0,05. Dengan demikian dapat disimpulkan bahwa model regresi tidak terjadi masalah heteroskedasitas.

\section{Pengujian Hipotesis}

\section{a) Uji F (Simultan)}

Uji ini digunakan untuk mengetahui apakah variabel independen (X1, X2,X3,) secara bersama-sama berpengaruh secara signifikan terhadap variabel dependen $(\mathrm{Y})$.

Tabel 4. Hasil uji nilai F

\begin{tabular}{|c|c|c|c|c|c|c|}
\hline \multicolumn{7}{|c|}{ Anova } \\
\hline & Model & $\begin{array}{l}\text { Sum of } \\
\text { squares }\end{array}$ & df & $\begin{array}{c}\text { Mean } \\
\text { Squares }\end{array}$ & $\mathbf{F}$ & Sig. \\
\hline 1. & Regression & 15,36 & 3 & 5,12 & \multirow{3}{*}{2,158} & \multirow{3}{*}{$.110 b$} \\
\hline & Residual & 85,415 & 36 & 2,373 & & \\
\hline & Total & 100,775 & 39 & & & \\
\hline 2. & Regression & 15,013 & 2 & 7,506 & \multirow{3}{*}{3,238} & \multirow{3}{*}{$.051 \mathrm{c}$} \\
\hline & Residual & 85,762 & 37 & 2,318 & & \\
\hline & Total & 100,775 & 39 & & & \\
\hline
\end{tabular}

b. Predictor (constanta): Pengetahuan, persepsi, dan alat pelindung diri

c. Predictor (constanta): Persepsi dan alat pelindung diri

Berdasarkan Tabel 4 diketahui koefisien determinasi (R2) adalah sebesar 0,149 atau 14,9\%. Dengan demikian dapat disimpulkan bahwa 14,9\% variabel-variabel bebas berpengaruh terhadap variabel terikat, sisanya sebesar 85,1\% dipengaruhi oleh varibel lain.

Tabel 5. Hasil uji koefisien determinasi

\begin{tabular}{|c|c|c|c|c|c|}
\hline \multicolumn{5}{|c|}{ Model Summary } \\
\hline Model & $\mathrm{R}$ & R Square & Adjust R Square & $\begin{array}{c}\text { Std. Error of the } \\
\text { Estimate }\end{array}$ & Durbin-Watson \\
\hline 1 & .386 & .149 & .103 & 1.522 & 1.156 \\
\hline
\end{tabular}




\section{b) Uji T (Parsial)}

Uji ini digunakan untuk mengetahui apakah dalam model regresi variabel independen $(\mathrm{X} 1, \mathrm{X} 2, \mathrm{X} 3)$ secara parsial berpengaruh signifikan terhadap variabel dependen $(\mathrm{Y})$.

Tabel 6. Hasil uji nilai T

\begin{tabular}{|c|c|c|c|c|c|c|c|}
\hline \multicolumn{8}{|c|}{ Coefficients } \\
\hline \multirow{2}{*}{ Model } & \multicolumn{2}{|c|}{ Unstandardized Coefficent } & \multirow{2}{*}{\begin{tabular}{|c|}
$\begin{array}{c}\text { standardized } \\
\text { Coefficent }\end{array}$ \\
Beta \\
\end{tabular}} & \multirow{2}{*}{$\mathrm{t}$} & \multirow{2}{*}{ sig } & \multicolumn{2}{|c|}{ Collinearity Statistic } \\
\hline & B & Std.eror & & & & Tollerance & VIF \\
\hline (Constanta) & 4,206 & 3,432 & & 1,226 & .228 & & \\
\hline pengetahuan & $-0,058$ & .151 & $-0,061$ & $-0,383$ & .704 & .930 & 1.074 \\
\hline persepsi & .543 & .234 & .725 & $-2,319$ & .026 & .241 & 4. 148 \\
\hline alat pelindung diri & $-0,489$ & .194 & $-0,083$ & $-2,523$ & .016 & .223 & 4.297 \\
\hline 2. (Constanta) & 3,797 & 3,223 & & 1,178 & .246 & & \\
\hline Persepsi & .529 & .228 & .706 & 2.314 & .026 & .247 & 4,046 \\
\hline Alat Pelindung diri & $-0,471$ & .186 & $-0,773$ & $-2,534$ & .016 & .247 & 4,046 \\
\hline
\end{tabular}

\section{Pengujian Koefisien Regresi Variabel Persepsi}

Tahapan dalam melakukan uji $\mathrm{t}$ adalah sebagai berikut :

1) Merumuskan Hipotesis :

Ho : Tidak ada pengaruh signifikan antara persepsi dengan perilaku kerja aman

H1 : Ada pengaruh signifikan antara persepsi dengan perilaku kerja aman

2. Tingkat signifikansi menggunakan $0,05(\alpha=5 \%)$

3. Berdasarkan Tabel 4.6 diperoleh t hitung persepsi sebesar 2,314

4. Tabel distribusi t dicari pada $\alpha=5 \%: 2=2,5 \%$ dengan df $40-4=36$, maka $t$ tabel sebesar 2,028

5. Kriteria pengujian : Ho diterima bila $t$ hitung $<\mathrm{t}$ tabel

$\mathrm{H} 1$ diterima bila t hitung $>\mathrm{t}$ tabel

6. $\quad$ t hitung $>\mathrm{t}$ tabel $(2,314>2,028)$ maka $\mathrm{H} 1$ diterima

7. Kesimpulan :

Karena t hitung $>\mathrm{t}$ tabel $(2,314>2,028)$ maka $\mathrm{H} 1$ diterima, ada pengaruh signifikan antara persepsi dengan perilaku kerja aman.

b. Pengujian Koefisien Regresi Variabel Alat Pelindung Diri

Tahapan dalam melakukan uji t adalah sebagai berikut :

1. Merumuskan Hipotesis :

H1 : Ada pengaruh signifikan antara alat pelindung diri dengan perilaku kerja aman

H0 : Tidak Ada pengaruh signifikan antara alat pelindung diri dengan perilaku kerja aman

2. Tingkat signifikansi menggunakan $0,05(\alpha=5 \%)$.

3. Berdasarkan Tabel 4.6 diperoleh t hitung alat pelindung diri sebesar -2.534. 
4. Tabel distribusi t dicari pada $a=5 \%: 2=2,5 \%$ dengan df $40-4=36$, maka $\mathrm{t}$ tabel sebesar 2,028.

5. Kriteria pengujian : $\quad$ Ho diterima bila t hitung $<$ t tabel

$\mathrm{H} 1$ diterima bila $\mathrm{t}$ hitung $>\mathrm{t}$ tabel

6. $\quad$ t hitung $<$ t tabel $(-2,534<2,048)$ maka H1 diterima

7. Kesimpulan :

Karena t hitung $<$ t tabel $(-2,534<2,048)$ maka $\mathrm{H} 1$ diterima. ada pengaruh signifikan antara alat pelindung diri dengan perilaku kerja aman. Karena nilai signifikasi Alat Pelindung Diri < 0.05 (5\%).

\section{Analisis Regresi Linier Berganda}

Metode analisis regresi linier berganda berdasarkan pengolahan data dengan menggunakan analisis regresi linier berganda, sebagai berikut :

Tabel 7. Rekapitulasi hasil pengolahan data dengan metode analisis regresi linier berganda

\begin{tabular}{|c|c|c|c|c|c|c|c|c|}
\hline \multirow{2}{*}{\multicolumn{2}{|c|}{ Variabel }} & \multicolumn{2}{|c|}{ nilai $R$ dan $R 2$} & \multicolumn{2}{|c|}{ nilai $F$} & \multirow{2}{*}{ Koef } & \multirow{2}{*}{ konst } & \multirow{2}{*}{ Keterangan } \\
\hline & & $\mathrm{R}$ & R2 & F Hitun & F tabel & & & \\
\hline $\mathrm{X} 2$ & \multirow{2}{*}{$\mathrm{Y}$} & \multirow{2}{*}{0,386} & \multirow{2}{*}{0,149} & \multirow{2}{*}{3,238} & \multirow{2}{*}{2,87} & 0,529 & \multirow{2}{*}{3,797} & Positif \\
\hline $\mathrm{x} 3$ & & & & & & $-0,471$ & & Negatif \\
\hline
\end{tabular}

Berdasarkan Tabel 7, maka persamaan regresi dapat dinyatakan sebagai berikut :

$$
\mathrm{Y}=3,797+0,529 \mathrm{X} 2-0,471 \mathrm{X} 3
$$

Persamaan tersebut menunjukkan bahwa jika :

1. Nilai Persepsi (X2) naik 1 poin dan diasumsikan nilai variabel lain (X3) tetap, maka nilai Perilaku Kerja Aman (Y) akan meningkat 0,529 poin.

2. Nilai Alat Pelindung Diri (X3) naik 1 poin dan diasumsikan nilai variabel lain (X2) tetap, maka nilai Perilaku Kerja Aman (Y) akan menurun -0,471 poin.

Dari penjelasan diatas dapat disimpulkan bahwa terdapat pengaruh positif variabel Persepsi dan varibel Alat pelindung diri.

Tabel 8. Rekapitulasi hasil uji asumsi klasik dan uji hipotesis

\begin{tabular}{|c|c|c|c|c|}
\hline \multirow[b]{2}{*}{ No } & \multirow[b]{2}{*}{ Jenis Pengolahan Data } & \multicolumn{2}{|c|}{ Variabel } & \multirow[b]{2}{*}{ Kesimpulan } \\
\hline & & Persepsi & $\begin{array}{c}\text { Alat } \\
\text { Pelindung } \\
\text { Diri }\end{array}$ & \\
\hline 1 & Uji Mulikolinearitas & $\begin{array}{l}\text { VIF } \\
4.046\end{array}$ & $\begin{array}{l}\mathrm{VIF} \\
4.046\end{array}$ & $\begin{array}{c}\text { Nilai VIF tiap variabel }<10, \\
\text { artinya model regresi tidak } \\
\text { menunjukkan adanya } \\
\text { multikolinearitas }\end{array}$ \\
\hline 2 & $\begin{array}{c}\mathrm{Uji} \\
\text { Heteroskedastisitas }\end{array}$ & $\begin{array}{r}\text { dapat } \\
\text { Gambar } \\
\text { sebara } \\
\text { memben }\end{array}$ & $\begin{array}{l}\text { hat pada } \\
\text { an Tabel 6, } \\
\text { itik tidak } \\
\text { pola/ alur }\end{array}$ & $\begin{array}{c}\text { Tidak terjadi } \\
\text { hetereoskedastisitas }\end{array}$ \\
\hline
\end{tabular}




\begin{tabular}{|c|c|c|c|c|}
\hline & & \multicolumn{2}{|c|}{$\begin{array}{c}\text { tertentu dan nilai } \\
\text { signifikasi kurang dari } \\
0,05\end{array}$} & \\
\hline 3 & Uji Normalitas & \multicolumn{2}{|c|}{$\begin{array}{c}\text { dapat dilihat pada tabel } \\
\text { 4.10, hasil uji one sample } \\
\text { kolmogorov-smirnov } \\
\text { dengan sig. } 0,200\end{array}$} & $\begin{array}{l}\text { Nilai sig. }>0,05 \text {, artinya data } \\
\text { berdistribusi normal. }\end{array}$ \\
\hline 4 & Uji F (Simultan) & \multicolumn{2}{|c|}{$\begin{aligned} \mathrm{F} \text { hitung } & >\mathrm{F} \text { tabel }(3,238 \\
& >2,87)\end{aligned}$} & $\mathrm{H}_{1}$ diterima \\
\hline 5 & Uji T (Parsial) & $\begin{array}{l}\text { t hitung }> \\
\mathrm{t} \text { tabel }\left(\mathrm{H}_{1}\right. \\
\text { diterima })\end{array}$ & $\begin{array}{l}\text { t hitung }<\mathrm{t} \\
\text { tabel }\left(\mathrm{H}_{0}\right. \\
\text { diterima })\end{array}$ & $\begin{array}{l}\text { Uji t untuk } \mathrm{X} 2 \text { menerima } \mathrm{H}_{1} \text { dan } \\
\qquad \mathrm{X} 3 \mathrm{H}_{0} \text { diterima }\end{array}$ \\
\hline
\end{tabular}

\section{B. Pembahasan}

Berdasarkan Tabel 8, maka evaluasi untuk metode regresi linier berganda adalah untuk uji asumsi klasik tidak ada masalah. Untuk uji normalitas dengan menggunakan uji one-sample Kolmogorov-Smirnov, diketahui bahwa nilai signifikan 0,200 atau $>0,05$ maka data terdistrubusi normal. Sementara uji multikolearinitas karena nilai VIF $<10$, maka model regresi tidak ditemukan adanya masalah multikolinearitas. Pada uji heteroskedastisitas dilihat pada gambar 4.1 sebaran titik tidak membentuk pola/ alur tertentu dan dan tabel 4.3 nilai signifikasi $<0$, model regresi tidak terjadi masalah heteroskedasitas. Untuk uji F, F hitung $>\mathrm{F}$ tabel $(3,238>2,87)$ maka H1 diterima, artinya variabel-variabel bebas (pengetahuan, persepsi dan alat pelindung diri) mempunyai pengaruh yang signifikan terhadap variabel terikat (perilaku kerja aman).

Untuk uji t, variabel persepsi dan alat pelindung diri berpengaruh terhadap perilaku kerja aman, dimana nilai signifikasi $<0,05$. Hasil penelitian ini sejalan dengan Kumala (2016), yang menyatakan bahwa terdapat hubungan bermakna antara persepsi terhadap risiko dengan perilaku aman. Hal ini juga memperjelas pernyataan Neal dan Griffin (2000), yang menyebutkan bahwa salah satu faktor yang dapat menjadi anteseden/activator dari kinerja keselamatan seseorang adalah kesadaran. Kesadaran memiliki keterkaitan yang erat dengan persepsi. Persepsi yang positif dan pemahaman yang tepat terhadap keselamatan dan kesehatan kerja di kalangan tenaga kerja merupakan unsur penentu kemajuan pelaksanaan keselamatan dan kesehatan kerja. Hasil penelitian ini juga sejalan dengan Nazrulzaman dan Hasibuan, (2017), yang menyatakan bahwa terdapat hubungan alat pelindung diri dengan perilaku aman. Hal ini juga memperjelas pernyataan Sahab (1997), bahwa sistem yang didalamnya terdapat manusia (sumber dan manusia) dan fasilitas merupakan salah satu hal yang penting dalam mewujudkan penerapan keselamatan di tempat kerja. 


\section{Simpulan}

Berdasarkan hasil analisis dan evaluasi yang telah dilakukan, maka dapat ditarik kesimpulan sebagai berikut:

1. Pengaruh pengetahuan, persepsi dan alat pelindung diri diketahui bahwa $\mathrm{F}$ hitung > F tabel $(3,238>2,87)$ dimana $\mathrm{H} 1$ diterima, artinya variabel-variabel bebas (persepsi dan alat pelindung diri) mempunyai pengaruh yang signifikan terhadap variabel terikat (perilaku kerja aman), dan didapat persamaan regresi $\mathrm{Y}=3,797+0,529 \mathrm{X} 2-0,471 \mathrm{X} 3$ dengan kesimpulan bahwa terdapat pengaruh positif variabel persepsi dan terdapat pengaruh negatif variabel alat pelindung diri terhadap perilaku kerja aman.

2. Dari hasil uji secara parsial masing-masing variabel independen terhadap variabel dependen diperoleh hasil bahwa faktor yang berpengaruh terhadap perilaku kerja aman adalah variabel persepsi dan alat pelindug diri karena nilai signifikasi $<0,05$.

\section{Daftar Pustaka}

Anizar. (2009). Teknik Keselamatan dan Kesehatan Kerja di Industri. Yogyakarta: Graha Ilmu.

Ansori, N., Novianti, T., Agustina, F., \& Ma'ruf, A.S. (2015). Model Prediksi Perilaku Kerja Aman Industri Kreatif Batik Tulis di Sumenep.

Bird, E., Frank, Germain, L., George. (1990). Practical Loss Control Leadership. Institute Publishing : Georgia.

Colling, D. (1990). Industrial Safety Management and Technology. Pentice Hall Inc.

Fitriani, A., \& Nawawiwetu, E.D. (2017). Hubungan Faktor Anteseden dan Konsekuensi dengan Safety Behavior di PT.X. Jurnal of Vocational Health Studies. 1, $50-57$.

Geller, E. (2001). The Pshychology Of Safety Handbook. USA : Lewis Publisher, Pp. $26-450$.

Griffin, M., Neal, \& Andrew., (2000). Perception of Safety at Work: Framework from Linking Safety Climate to Safety Performance, Knowledge, and Motivation. Journal of Motivational Health Psychology, 5(3), 347-358.

Ghozali, I., (2007). Aplikasi Analisis Multivariate Dengan Program SPSS. Semarang: Badan Penerbit Universitas Diponegoro. 
Green, L.W. (1980). Health Education Planning, A Diagnostic Approach.California: Mayfield Publishing Company. 